$1-1-2020$

\title{
Designing Policy Solutions to Build a Healthier Rural America
}

\author{
Sameer Vohra \\ UGA Associate Provost for Faculty Affairs \& Charles H. Kirbo Chair in Law Southern Illinois University \\ School of Medicine \\ Carolyn Ponter \\ UGA Associate Provost for Faculty Affairs \& Charles H. Kirbo Chair in Law Southern Illinois University \\ School of Medicine \\ Amanda Fogleman \\ UGA Associate Provost for Faculty Affairs \& Charles H. Kirbo Chair in Law Southern Illinois University \\ School of Medicine \\ Thomas Albers \\ UGA Associate Provost for Faculty Affairs \& Charles H. Kirbo Chair in Law Southern Illinois University \\ School of Medicine \\ Anish Patel \\ UGA Associate Provost for Faculty Affairs \& Charles H. Kirbo Chair in Law
}

See next page for additional authors

p bepress

\section{Repository Citation}

Sameer Vohra, Carolyn Ponter, Amanda Fogleman, Thomas Albers, Anish Patel, and Elizabeth Weeks, Designing Policy Solutions to Build a Healthier Rural America , 48 J. L. Med. \& Ethics 491 (2020), Available at: https://digitalcommons.law.uga.edu/fac_artchop/1339

This Article is brought to you for free and open access by the Faculty Scholarship at Digital Commons @ University of Georgia School of Law. It has been accepted for inclusion in Scholarly Works by an authorized administrator of Digital Commons @ University of Georgia School of Law. Please share how you have benefited from this access For more information, please contact tstriepe@uga.edu. 


\section{Authors}

Sameer Vohra, Carolyn Ponter, Amanda Fogleman, Thomas Albers, Anish Patel, and Elizabeth Weeks 
Designing

Policy Solutions

to Build a

Healthier Rural

America

Sameer Vohra, Carolyn Pointer,

Amanda Fogleman,

Thomas Albers, Anish Patel,

and Elizabeth Weeks

\section{Introduction}

Disparities exist in the livelihood and opportunities for people living in America's rural communities. These differences result in a much sicker rural America compared to its urban counterpart. Rural counties have higher rates of smoking, obesity, child poverty, and teen pregnancies than urban counties. ${ }^{1}$ More uninsured adults live in rural areas, causing rural hospitals to close and/or cut vital services such as obstetrics care. ${ }^{2}$ Rural hospitals also provide fewer mental health services. ${ }^{3}$ The result is Americans living in rural areas are more likely to die from the five leading causes of death than those living in urban areas: heart disease, cancer, unintentional injuries, chronic lower respiratory disease, and stroke. ${ }^{4}$ Depending on the definition of rural, between 46-60 million people, or approximately 15-20 percent of the U.S. population, live in rural communities. ${ }^{5}$ Rural communities exist in nearly every state with great variability in their culture, economics, and social conditions. In fact, 97 percent of the country's land mass is rural. ${ }^{6}$

Despite the ubiquity of rural America, much of the discourse surrounding these communities focuses on dissolution rather than reinvigoration. Headlines over the past year have included, "The real (surprisingly comforting) reason rural America is doomed to decline,"7 "The Hard Truths of Trying to 'Save' the Rural Economy," and "Rural America is the New 'Inner City."9 These headlines are part of a growing, mostly urban, discourse on whether rural communities are worth saving at all.

Sameer Vohra, M.D., J.D., M.A., F.A.A.P., is the Founding Chair of Southern Illinois University School of Medicine's (SIU SOM) Department of Population Science and Policy. A general pediatrician, Dr. Vohra is also an Associate Professor of Pediatrics, Medical Humanities, and Law. Dr. Vohra completed a residency in pediatrics at the University of Chicago (Chicago, IL), as well as earning a Master of Arts in public policy at the University of Chicago (Chicago, IL), a medical doctorate at SIU SOM (Springfield, IL), a juris doctorate, graduating first in his class, at SIU School of Law (Carbondale, IL), and a Bachelor of Arts with honors at Northwestern University (Evanston, IL). Carolyn Pointer, J.D., is an Assistant Professor in Medical Humanities, and the Policy Director in the Department of Population Science and Policy at the SIU School of Medicine (Springfield, IL). Her background in Medical-Legal Partnerships focuses her work on the social determinants of health. Professor Pointer earned her J.D. from Boston University School of Law (Boston, MA), and a Bachelor of Science with honors at the Boston University School of Education (Boston, MA). Amanda Fogleman, M.Eng., Senior Research Project Coordinator, is one of the founding members of Southern Illinois University (SIU) Medicine's Department of Population Science and Policy (Springfield, IL). Ms. Fogleman graduated from Southern Illinois University Edwardsville (Edwardsville, IL) with a Bachelor of Science in Biology and the University of Illinois Chicago Continued on page 492 
The dialogue on rural communities needs to change. America's rural residents deserve more attention. With a 2020 election focused on defining the future of this American century, a new energy and focus should be spent on designing, capturing, and spreading existing and new innovations occurring in rural communi- and age - collectively referred to as the social determinants of health. ${ }^{11}$ Attention is now being focused on poverty, lack of insurance, low educational attainment, unsafe or unstable housing, poor nutrition, and unemployment - all of which are social conditions directly linked with shorter lives, as well as disparities in health care access and outcomes. ${ }^{12}$ Substantial value exists in focusing the energy of innovation in rural communities around health - working towards building a novel and sustainable policy approach aimed at reducing disparities and achieving health equity.

This paper aims to provide a framework for policy solutions to build a healthier rural America. First, the authors describe in detail the health challenges occurring in rural communities and the great disparity that exists between rural and urban health measures. Second, they describe the varying definitions of rural and how this inconsistency in definition leads to greater difficulties in solution design. Third, the authors describe the current state of rural health policy, especially as it relates to current payment mechanisms for hospitals and providers. Finally, they describe innovative policies and practices in states addressing rural

ties. These innovations need a nonpartisan unifying force - an issue central to the thoughts and actions of all citizens. This unifying issue also needs to intersect seamlessly with other social and political areas in a manner by which its improvement also improves other levers of society.

In anticipation of the 2020 election, it is clear the top issue on the minds of voters is health and health care. ${ }^{10}$ The incredible challenges recently brought on by the COVID-19 pandemic have only magnified its importance. Health scholars also know that health is influenced by both the provision of health care and the conditions by which people are born, grow, live, work, health challenges and how many of them could be a model for the country.

\section{Rural Health Disparities}

Rural Americans face a variety of complex health issues, many of which occur at higher rates in rural communities compared to urban communities, ${ }^{13}$ and the health gap continues to widen. ${ }^{14}$ In recent years, disparities in life expectancy and mortality have grown, further worsening the health outcomes of individuals living in rural America. ${ }^{15}$ According to the Centers for Disease Control and Prevention (CDC), many of the causes of death that disproportionately affect rural

Continued from page 491 with a Master of Engineering in Bioinformatics (Chicago, IL). T.J. Albers, M.A., is a Health Policy Coordinator at Southern Illinois University School of Medicine's Department of Population Science and Policy. He received his B.A. from Illinois College (Jacksonville, IL) and M.A. from University of Illinois - Springfield (Springfield, IL). His research focuses on rural health care delivery, policy development, and addressing rural health disparities. Anish Patel $i$ s a J.D candidate at the University of Georgia School of Law (Athens, Georgia). He received his B.S. in Chemistry from the University of Georgia (Athens, Georgia). He previously worked as a Research Chemist at the U.S. Centers for Disease Control and Prevention (Atlanta, Georgia). Elizabeth Weeks, J.D., is Associate Provost for Faculty Affairs and Charles H. Kirbo Chair in Law at the University of Georgia School of Law (Athens, Georgia). She received her B. A. from Columbia University (New York, New York) and JD from the University of Georgia School ofLaw (Athens, Georgia). She previously served on the faculty of the University of Kansas School of Law (Lawrence, Kansas), where she was director of the medical-legal partnership clinic and has visited at University of the Pacific-McGeorge School of Law (Sacramento, California). Her research and teaching focus is in health care financing and regulation and public health law. 
areas could have been prevented, including as many as 25,000 deaths from heart disease, 19,000 from cancer, and 12,000 from unintentional injuries. ${ }^{16}$

Rural-urban disparities also present in children's health outcomes. Rural children have a higher rate of exposure to adverse childhood experiences, including parental separation/divorce, parental death, household incarceration, household violence, household mental illness, household substance abuse, and economic hardship. ${ }^{17}$ An example of an adverse childhood experience that children encounter is poverty. Whereas $17.7 \%$ of urban children lived in poverty in $2017,22.8 \%$ of rural children lived in poverty, a rate of 1.3 times greater. ${ }^{18}$

Consequently, adverse childhood experiences could have both an immediate impact during childhood and contribute to poor adult health outcomes. Higher mortality incidence exists in rural counties compared to urban counties for infants, children, and young adults. ${ }^{19}$ Fontanella et al. ${ }^{20}$ found that suicide rates for adolescents are higher in rural than in urban communities. Such findings paint a challenging picture for rural youth.

The reasons behind these rural-urban health disparities start with the challenging socioeconomic conditions of many communities. A higher percentage of children in rural areas compared with urban areas have parents who experience financial difficulties meeting basic needs such as food and housing. ${ }^{21}$ Children in rural areas also more often lack amenities and live in neighborhoods in poor condition..$^{22}$ These poor socioeconomic conditions lead to rural residents having a poor foundation to build healthy lives.

In addition, the rural health disparities become magnified when you also add the smaller and often under-resourced healthcare infrastructure. ${ }^{23}$ Specifically, rural communities struggle with healthcare coverage, ${ }^{24}$ workforce shortages,${ }^{25}$ and delays in accessing treatment. ${ }^{26}$

Beginning with health insurance, individuals living in rural counties have significantly lower healthcare coverage than those living in suburban and mediumsized communities. ${ }^{27}$ Another factor is that rural communities are simply under resourced with healthcare providers. For instance, Petterson and colleagues reported that rural areas only have about 68 primary care physicians per 100,000 people, compared to an average of 80 per 100,000 in urban regions. ${ }^{28}$ The shortage of behavioral health professionals is even more pronounced between rural and urban areas. While metropolitan areas have 33.2 psychologists and 17.5 psychiatrists per 100,000 people, rural areas only have 9.1 psychologists and 3.4 psychiatrists per 100,000 people. ${ }^{29}$
Despite health concerns in rural America, research indicates that residents in rural areas feel positive about the future. Although $55 \%$ of rural Americans rate their local economy as fair or poor, ${ }^{30} 82 \%$ of rural Americans indicate that their local population has either increased or stayed the same over the past five years. In addition, the majority of rural residents reflect positively on their community by way of feeling attached to it (81\%) and receiving help from community members $(67 \%)$. These signs show that rural communities are eager for the investment necessary to keep their communities' stories alive. This investment should start with the health of their communities.

\section{The Challenge to Define Rural}

The road to a healthier rural America needs to start at the most basic level - clarifying what areas and populations are considered rural. Currently, the word rural or even rurality has many different definitions, as the words often change in meaning depending on who you ask or the context used. This definition or lack thereof is problematic as government entities, philanthropies, and other funders often use different, and conflicting, definitions in allocating resources. Specificity with appropriate adaptability are critical in ensuring that both the public and policymakers have the same understanding of what a rural community means.

For example, Robert Wood Johnson Foundation's County Health Rankings uses the U.S. Census Bureau's definition of rural. The Census Bureau defines rural as anything that is not urban (greater than 2,500 people)..$^{31} \mathrm{~A} 2016$ policy brief published by the US Census Bureau uses the case study of Stanley County, South Dakota, to illustrate how this definition can be problematic. ${ }^{32}$ Stanley County has a population of only 2,994 people but about $70 \%$ of the residents live in one location, Fort Pierre. Therefore, despite this low population number, Stanley County by the Census Bureau's definition, more closely resembles an urban hub, similar to Cook County, Illinois (home of Chicago), and San Diego County, California (home to San Diego), than other rural communities. ${ }^{33}$ On the other hand, the Office of Management and Budget (OMB) defines counties as either metropolitan (population core greater than 50,000), micropolitan (greater than 10,000 but less than 50,000 people), and non-core (less than 10,000). ${ }^{34}$

In both cases, the word rural seems to be missing from the definition, and therefore, it is difficult to understand what a rural community actually is. Even if we take everything that is non-urban, non-metropolitan, and non-micropolitan to be rural, the definitions are still inconsistent - the Census Bureau would 
place non-urban as less than 2,500 and OMB as less than 10,000. This difference can cause a discrepancy for up to 50 million people depending on the definition used. 35

To further confuse the matter, many federal programs use combinations of rural definitions or standard Census or OMB definitions with additional qualifiers. The Federal Office of Rural Health Policy (FORHP) uses the non-metropolitan OMB definition along with Rural-Urban Commuting Areas (RUCA). RUCA looks at census tracts instead of counties to further distinguish rural areas that may be within metropolitan areas. FORHP also takes into account daily commuting, urbanization, and population density. ${ }^{36}$ One notice of funding opportunity on FORHP's website for rural residency planning and development programs defined America's rural population as 46 million while the Census Bureau reports 60 million people live in rural areas.37 This could leave over 15 million rural dwelling residents without the opportunity to attract future providers to their communities, which is unfortunate considering most rural areas are classified as physician shortage areas.

A further complicating factor is that these definitions do not even begin to provide a description of what it means for a community to be designated "rural." Sociologists define "community" as a group of people with shared interests, shared geography, and strong interpersonal bonds. ${ }^{38}$ By defining rural in terms of population alone, it leads many individuals to believe that rural areas are homogenous with all residents sharing a similar faith, race, and values. This could not be farther from the truth. A rural community in the Midwest is very different from a rural community on the frontier or a rural community in the Mississippi Delta. These different communities also are dependent on different economic realities, whether they be agriculture, tourism, mining, and manufacturing. ${ }^{39}$ The differences that exist in culture and economy between our country's rural communities also lead to unique challenges in rural health and wellness.

There are some resources that try to help. Zahnd et al. published a comprehensive look at the most frequently used rural-urban measures and their advantages and disadvantages in 2019.40 Additionally, the Rural Health Information Hub has a tool to determine if a community qualifies as rural for federal programs including FORHP grants. This tool allows you to determine where a community falls on the ruralurban spectrum based on several different definitions. It also allows you to determine if the community is a health professional shortage area. ${ }^{41}$
Rural America is unique, dynamic, beautiful, and essential to the health of our country. Health officials and researchers are making public policy based on governmental definitions constructed for purposes other than health services. Moreover, the policies are not always tailored to the particular demographics and dynamics of communities. The result is often inconsistency and confusion with many communities not able to access the people, services, and resources that they desperately need. One standard federal and state definition with appropriate adaptability would allow for resources to be allocated more effectively and efficiently.

\section{Rural Health Policy Designations}

Despite the difficulty defining rural in a consistent or descriptively accurate way, the term in its different classifications has salience for health policy. Repeatedly, law- and policymakers have recognized the need for a different set of rules, designations, incentives, and reimbursement methodologies for rural areas, defining eligible entities according to very specific, but not always consistent sets of criteria. Thus, these designations, while helpful, exacerbate the lack of uniformity in defining what we mean by "rural" and who benefits from policies aimed at such areas.

However, broadly speaking, repeated implementation of special rural policies implicitly recognizes the unique health disparities affecting rural residents and the related health care access challenges. We describe several of these designations below to illustrate both policy recognition of rural health care challenges but also the limitations of these protections and need for additional reforms, as proposed in the final part of this article. We first describe special designations for hospitals, then primary care and other outpatient services critical to rural providers.

\section{Sole Community Hospital Designation}

One of the earliest special designations relevant to rural providers is the Sole Community Hospital ( $\mathrm{SCH}$ ) designation. Congress created the $\mathrm{SCH}$ program in 1983 to support short-term general hospitals that "by reason of factors such as isolated location, weather conditions, travel conditions, or absence of other hospitals, is the sole source of inpatient hospital services reasonably available in a geographic area to Medicare beneficiaries." ${ }^{42} \mathrm{SCH}$ receive higher Medicare reimbursement for both inpatient and outpatient services. In addition, SCHs qualify for adjustments based on patient volume and participation in other federal reimbursement incentives. ${ }^{43}$ The continued Congressional recognition of $\mathrm{SCHs}$ through those allowances 
signals a well-established federal commitment to rural hospitals and to ensuring access to care in rural areas.

A hospital is eligible for $\mathrm{SCH}$ status if it: (1) "is located more than 50 miles from other hospitals;" (2) is located between 25 and 50 miles from other hospitals and either: no more than 25 percent of the residents in the hospital's service area are admitted to other hospitals for care, or because of local topography, weather, and other considerations, the other hospitals are not accessible for more than one month during a 12-month period; or (3) "is located between 15 and 25 miles from other hospitals and because of local topography, weather, etc., the other hospitals are generally not accessible for more than 1 month during a 12-month period." 44

$\mathrm{SCHs}$ are eligible to receive the higher of two possible reimbursement rates: (1) the Inpatient Prospective Payment System (IPPS) rate under which other Medicare-participating hospitals are reimbursed, which includes certain geographic adjustments for the area wage-index and local costs, or (2) an updated hospital-specific rate, based on the hospital's costs in a base year, updated to the current year and adjusted for changes in the case mix. ${ }^{45}$

\section{Rural Referral Centers}

Another special category for rural hospitals, created at the same time as SCHs, was Congress's Rural Referral Center (RRC) designation. ${ }^{46}$ The RRC program "was established to support high-volume rural hospitals that treat a large number of complicated cases." ${ }^{47}$ RRCs enjoy several benefits including a higher standardized payment rate, exemption from proximity requirements, exemption from the $12 \%$ payment adjustment cap that applies to other rural hospitals, and eligibility to participate in the $340 \mathrm{~B}$ drug program (discussed below) at a lower rate. ${ }^{48}$

A hospital must be in a rural area to qualify for the RRC designation. A rural hospital can qualify for RRC designation in three ways. First, rural hospitals with at least 275 beds qualify. Second, if the hospital demonstrates: “(1) at least 50 percent of the hospital's Medicare patients are referred by physicians who are not employed by the hospital; (2) at least 60 percent of the hospital's Medicare patients live more than 25 miles from the hospital, and (3) at least 60 percent of all services provided to Medicare patients are provided to patients who live more than 25 miles from the hospital." The third way to qualify is by demonstrating that the hospital (1) "has a Case-Mix Index (CMI) equaling the lower of the median CMI value for all urban hospitals nationally or the median CMI value for urban hospitals located in its region;" and (2) discharges at least 5.000 patients annually (or 3,000 for an osteopathic hospital) or the median number of discharges for urban hospitals in its same census region and "(a) more than 50 percent of its active staff are specialists as specified by 42 CFR 412.96(c)(3); (b) at least 60 percent of all discharges are for patients who live more than 25 miles from the hospital; or (c) at least 40 percent of all inpatients treated are referred from other hospitals or from physicians who are not on the hospital's staff." 49

RRCs are high-volume acute care rural hospitals with large numbers of complicated cases. By creating reimbursement and other structures to support these facilities, RRCs "localize care, minimize the need for further referrals and travel to urban areas, and provide services at costs lower than would be incurred in urban areas." ${ }^{\circ 0}$ As larger facilities, they typically also support "satellite sites and outreach clinics to provide primary and emergency care services to surrounding underserved communities." ${ }^{51} \mathrm{RRCs}$ often are essential to local economies, serving as major employers and making the community more attractive to businesses or residents looking to relocate. Approximately 135 hospitals in 38 states have RRC status. ${ }^{52}$

\section{Critical Access Hospital Designation}

Even with the $\mathrm{SCH}$ and $\mathrm{RCC}$ designations, rural health care delivery continued to be challenging. A more recent designation for rural hospitals is Critical Access Hospitals (CAHs). ${ }^{53}$ The Balanced Budget Act of 1997 stated that in order to obtain CAH designation the nonprofit or public hospital must be: (1) "located more than a 35-mile drive from a hospital;" (2) "certified by the State as being a necessary provider of health care services to residents in the area;" (3) make "available 24-hour emergency care" services as determined necessary by the State; (4) have no more than 25 acute care inpatient beds; and (5) provide an average length of stay of 96 hours or less for acute care patients. ${ }^{54}$ A CAH receives certain benefits so as to "reduce the financial vulnerability of rural hospitals and improve access to healthcare by keeping essential services in rural communities." ${ }_{55}$

The biggest advantage for CAHs is cost-based reimbursement. Historically, since the beginning of the Medicare and Medicaid programs in 1965, the government paid all providers on a cost basis, meaning that for every dollar spent, the provider submitted a bill to the government and recovered the amount charged. Cost-based reimbursement has an obvious inflationary incentive - spend more, receive more - which came under scrutiny as health care costs continued to rise. 
In the early 1980 s, the federal Centers for Medicare and Medicaid Services (CMS) adopted a different approach for Medicare hospital reimbursement - the inpatient prospective payment system (IPPS). Under IPPS, hospitals receive a predetermined, bundled payment, based on the average cost of treating certain conditions, coded according to diagnosis-related groups (DRGs). The average DRG rate is adjusted for particular features of the hospital, including status as a disproportionate share (DSH) hospital, teaching hospital, or transplant hospital, as well as geographic wage variations and other overhead costs. The intended effect of IPPS is to reduce spending and encourage efficiency. Hospitals that manage to treat patients for lower costs than the predetermined amount may retain the excess, while hospitals that spend more, must absorb those extra costs (subject to an additional possible adjustment for designated "outlier" cases). IPPS is considered a success in reducing Medicare costs, and similar prospective payment systems have been adopted across other services (including outpatient, mental health, and other providers) and payers (including private insurers).

The CAH designation, however, allows hospitals to revert to the pre-IPPS cost-based reimbursement methodology, which may allow those essential providers to stay in the black. Those hospitals receive costs plus one-percent for Medicare patients, and, depending on the state, may also receive cost-based reimbursement from Medicaid. Again, the designation recognizes that rural hospitals are essential to their communities and operate under different financial and other pressures, as compared to urban hospitals that do not meet the five criteria above.

\section{Rural Community Hospital Designation}

Congress again recognized the need for an additional special designation for rural hospitals in 2003. Rural Community Hospitals ( $\mathrm{RCHs}$ ) include hospitals that are considered too large to be designated CAHs. ${ }^{56}$ The $\mathrm{RCH}$ program is a demonstration project, initiated under the Medicare Modernization Act of 2003. ${ }^{57}$ Initially, hospitals were invited to apply for a five-year period, ${ }^{58}$ and the statute authorized thirty hospitals to participate..$^{59}$ The program has since been renewed twice, for additional five-year periods. The demonstration was established "to test the feasibility and advisability of establishing rural community hospitals to furnish covered inpatient hospital services to Medicare beneficiaries." The demonstration project and its repeated renewals highlight the ongoing financial challenges rural hospitals face.
Part of the $\mathrm{RCH}$ program's goals include "caring for underserved individuals (because of those individuals' geographic or economic status)" and the entire rural community as well. ${ }^{60}$ Because the program "focuses on promoting high quality and efficient healthcare delivery..., applicants are asked to specify interventions that both increase access to and improve the quality of care, while enhancing patient care options and the ability for beneficiaries to remain in their own rural communities."61 The third round of solicitations gives priority to hospitals located in one of the twenty states with the lowest population densities. ${ }^{62}$

The requirements for a hospital to receive $\mathrm{RCH}$ designation include: (1) "located in a rural area" (as defined by the Social Security Act); (2) "fewer than 51 acute care inpatient beds" (excluding psychiatric and rehabilitation unit beds); (3) 24-hour emergency care services; and (4) not eligible for designation, or has not been designated, as a critical access hospital" under section 1820 of the Social Security Act. ${ }^{63}$ As with CAHs, the main advantage of the $\mathrm{RCH}$ designation is cost-based reimbursement, which applies to the first cost-reporting period of the demonstration project. For subsequent cost-reporting periods, participating $\mathrm{RCHs}$ receive the lesser of reasonable costs or a target amount. The target amount is defined as the preceding cost reporting period's target amount increased by the IPPS update factor (which would apply to other hospitals paid under IPPS) for that particular cost reporting period. ${ }^{64}$

The RCH demonstration, and subsequent renewals, provide evidence that federal policy recognizes the unique status of rural hospitals and continuing need to modify standard approaches to reimbursement and delivery for medical care in rural areas.

\section{OB Drug Pricing Programs}

A critical support for rural hospitals is the $340 \mathrm{~B}$ Drug Pricing Program (340B). 340B encourages hospitals to divert resources saved from reduced drug prices toward improved care for vulnerable populations including but not limited to lower-income patients. The program was created in 1992 and approximately forty-two percent of general acute hospitals have been participating since 2012. 340B helps qualifying hospitals gain more resources by making it cheaper for them to purchase outpatient drugs while receiving standard reimbursement for those drugs. ${ }^{65}$

Organizations that are eligible for $340 \mathrm{~B}$ include community health centers, children's hospitals, hemophilia treatment centers, CAHs, SCHs, RRCs, and public and non-profit DSH hospitals that serve lowincome and indigent populations. Enrolled hospitals 
can achieve an average of 25 to 50 percent savings on pharmaceutical purchases. ${ }^{66}$ The $340 \mathrm{~B}$ program is critical to rural hospitals' financial viability. ${ }^{67}$ Even though generating relatively modest annual savings of $\$ 10,000$, this amount can make the difference between a rural hospital staying open or having to close its doors. ${ }^{68}$

\section{Rural Health Clinics}

In addition to the above-described hospital designations, Congress has recognized that rural primary care and other outpatient services need different policies. The Rural Health Clinic (RHC) designation was created in 1977 to "increase access to primary care for patients in rural communities." 69 RHCs provide patients with an integrated team of cross-disciplinary members consisting of physicians, nurse practitioners, physician assistants, certified nurse-midwives, and clinical social workers. ${ }^{70}$ By providing access to these other mid-level providers, RHCs combat the vacuum in care for Medicare and Medicaid patients created by the physician shortage in rural areas. ${ }^{71}$ The main advantage of RHCs is higher reimbursement rates under Medicare. ${ }^{72}$

RHC visits must be medically necessary, face-toface, and related to a "service that requires the skill level of the RHC practitioner." ${ }^{3}$ In order to qualify as an RHC, a clinic must (1) be located in a rural area and (2) "employ an NP or PA, (3) have an NP, PA, or $\mathrm{CNM}$ working at least 50 percent of the time during operational hours, (4) "directly provide routine diagnostic and laboratory services (5) have arrangements with one or more hospitals to provide medically necessary services unavailable at the RHC, (6) "have drugs and biologicals available to treat emergencies," (7) provide various laboratory tests on site, (8) "have a quality assessment and performance improvement program, (9) post operation days and hours, (10 not be primarily a mental disease treatment facility or a rehabilitation agency, (11) not be a Federally Qualified Health Center, and (12) meet all other state and Federal requirements. ${ }^{74}$

\section{Federally Qualified Health Centers}

Federally Qualified Health Centers (FQHCs) are another designation important for safety net providers. The designation is not limited to rural areas but also applies to medically underserved urban areas. FQHCs provide a broader range of services than RHCs, including diagnostic and laboratory testing, pharmaceuticals, behavioral and oral health, hospital and specialty care, after-hours care, case management, transportation, and interpretative services. RHCs, by contrast, provide primary outpatient care, basic laboratory services, and emergency care..$^{75}$

The FQHC designation was created in $1965^{76}$ and supports outpatient services, including community health centers, migrant health care centers, community health centers for the homeless, public housing primary care clinics, and similar facilities. ${ }^{77}$ FQHCs are required to accept all patients. ${ }^{78}$ In order to qualify, the clinic must "offer services to all, regardless of the person's ability to pay, establish a sliding fee discount program, be a nonprofit or public organization, be community-based, serve a medically underserved area or population, provide comprehensive primary care services, and have an ongoing quality assurance program."79 The main benefit for FQHC status designation is a separate FQHC PPS. ${ }^{80}$ States also may establish alternative reimbursement methodologies for FQHCs for Medicaid-related expenses. ${ }^{81}$

These descriptions demonstrate repeated federal policy attention to the challenges of rural health care delivery; however, they still fail to fully protect those providers from financial insolvency. The loss of a hospital, or lack of essential primary care, obstetric, emergency, mental health, or other care in a rural community imperils not only the health of that community but also its economic viability. Hospitals often are critical employers in rural towns. Moreover, it may be impossible to attract new industry, retirement communities, or other economic lifelines without essential medical services in the area. The next section describes these remaining challenges in more detail.

\section{Challenges Remain}

Despite the above-described designations aimed at supporting and sustaining rural health providers, the landscape remains treacherous. Since 2010, the year that the Patient Protection and Affordable Care Act took effect, thirty-six states have seen at least one rural hospital close in the United States, for a total of 172 as of May 2020.82 Those closures are concentrated in the South and other states that declined to expand Medicaid after the U.S. Supreme Court's decision in NFIB $v$. Sebelius.

Those demographic and economic development trends have particular impacts for rural health care delivery, access, and sustainability. Existing health care financing and organization models are failing to serve the increasingly elderly, child-less, impoverished, and economically disadvantaged residents of rural communities. Stories are all too common of a rural resident having to take an entire day off of work to travel to a primary care physician appointment, assuming she can find someone to see her. ${ }^{83}$ Families 
may be reluctant to take young children to visit grandparents in rural areas because of the lack of access to emergency medical care. Physicians write prescriptions for rural patients instead of ordering physical therapy, patient counseling, or other interventions that require more regular follow-up. Overprescribing feeds the opioid epidemic, with physicians prescribing pain pills for non-acute aches and pains rather than physical therapy, often writing for prescriptions for thirty or sixty days, rather than five or six. Women who experience complications during deliveries may face drastically adverse outcomes from conditions that could have been effectively managed in an urban medical center. ${ }^{84}$ series of innovative state-based programs and policies that may be the start of a more concentrated federal action to improve the health of rural communities. The suggestions below are not exhaustive but could serve as the beginning of a series of investments that the federal government can make to address disparities and improve the health and vitality of rural communities.

\section{Redefining Rural}

As noted in discussions above, any policy aimed at "rural" communities will need to grapple with how the term is defined and applied. Although no concrete answer to this complicated problem has emerged, a framework has been recently developed by the Rural

As noted in discussions above, any policy aimed at "rural" communities will need to grapple with how the term is defined and applied. Although no concrete answer to this complicated problem has emerged, a framework has been recently developed by the Rural Policy Research Institute (RUPRI) that focuses on crafting tailored definitions based on the relationships between where people live, where health care happens, and how it is delivered. The RUPRI panel recommends that policymakers consider legislative and regulatory definitions of rural that account for demographic change while maintaining programmatic objectives.

\section{Federal and State Policy Solutions to Improve Rural Health}

Despite Congress's efforts to stabilize rural health providers, it is clear that rural communities remain both underserved and less healthy. As referenced earlier, rural counties continue to have higher rates of smoking, obesity, child poverty, and teen pregnancies than urban counties. ${ }^{85}$ The current result is that Americans living in rural areas are more likely to die from the five leading causes of death than those living in urban areas: heart disease, cancer, unintentional injuries, chronic lower respiratory disease, and stroke. ${ }^{86}$ More needs to happen to protect the health of rural residents, addressing both health disparities and health care access, two concepts that are interconnected.

Many states have expanded their view on how to improve rural health, using innovative programs and policies to pilot ideas that aim to improve not just the way to finance rural health care delivery but also to address the social issues affecting a community's health. With the many and diverse health challenges affecting our rural communities, the authors offer a
Policy Research Institute (RUPRI) that focuses on crafting tailored definitions based on the relationships between where people live, where health care happens, and how it is delivered. The RUPRI panel recommends that policymakers consider legislative and regulatory definitions of rural that account for demographic change while maintaining programmatic objectives. ${ }^{87}$

The RUPRI panel also recommends the following additional suggestions that could be used to refine the definition of rural: (1) Define rural based on policy or program purposes and goals, creating incremental, informed changes that do not disrupt existing programs or create instability in research, practice, and policy; (2) retain current frameworks for defining rural but consider additional criteria to meet specific programs and objectives; (3) index rural/ urban definition thresholds to population growth to allow the definitions to adapt and change over time; (4) consider updated measures of interdependence between metropolitan and non-metropolitan areas; (5) use non-census data sets including productivity or 
employment data to better understand and measure economic interconnectedness; and (6) oversample rural populations similar to minority and underserved populations in census-based and other federal datasets to make margin of errors smaller.

\section{New Models to Fund Rural Hospitals}

Many problems with the rural healthcare delivery system stem from challenges that rural hospitals face, including but not limited to declining patient admissions, physician shortages in rural areas, highly specialized inpatient care, and an increase in outpatient services reimbursed at lower margins than inpatient care.

Rural hospitals play a very important role in communities. In addition to their provision of health care services, rural hospitals often serve as the economic hubs of those communities. Using the State of Illinois as an example, the U.S. Census found one in four residents are employed by education, health care, and social services in non-metro counties. ${ }^{88}$ Small and/ or rural hospitals in Illinois pump $\$ 2.5$ billion into state and local economies via employee salaries and benefits. ${ }^{89}$ Hospital employees generate $\$ 3.5$ billion in economic activity for the state in the form of increased buying power. Small and rural hospitals create over 32,000 direct jobs and 42,000 indirect jobs in Illinois. ${ }^{90}$ Furthermore, these hospitals spent $\$ 2.1$ billion on goods and services annually, generating $\$ 3$ billion in economic activity. ${ }^{91}$

For these reasons, rural hospitals are essential to the economic viability and health of their service areas. When a community loses its hospital, per capita income falls $4 \%$ and the unemployment rate rises more than $1.5 \% .{ }^{92} \mathrm{~A}$ recent study found that $21 \%$ of rural hospitals in the U.S. are at a high risk of closing due to their financial situation (operating margin, days cash on hand, and debt-to-capitalization ratio). ${ }^{93}$ A multitude of factors are driving this crisis, including but not limited to a degradation of the payer mix and the inability to leverage innovation. In Illinois, 13 of the 75 rural hospitals are at risk of closure (17.3\%), and of those at risk, $31 \%$ are essential ${ }^{94}$ to their communities. ${ }^{95}$

The critical differentiator in the above-described rural provider designations is alternate reimbursement methodologies. Yet even those have not proven to be enough to keep facilities in business. One new, innovative approach to stabilizing hospital income is the Maryland "Global Budget Revenue" (GBR) methodology. Maryland has the only all-payer hospital rate regulation system in the country. A 36-year-old Medicare waiver exempts Maryland from the Inpa-
Figure

Figure I displays the Conceptual framework for Maryland All-Payer Model evaluation. ${ }^{115}$

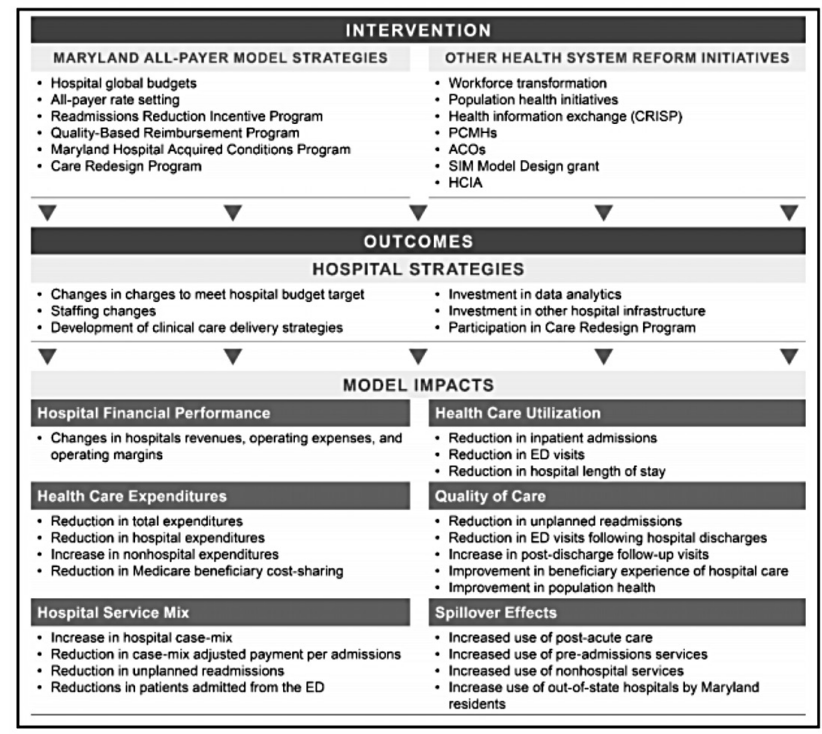

tient Prospective Payment System (IPPS) and Outpatient Prospective Payment System (OPPS) and allows Maryland to set rates. Under the waiver, all third parties pay the same rate.

The Maryland All-Payer Model pushed hospitals to begin to use (or increase usage of) community health workers, discharge planners, care coordinators, and social workers. ${ }^{96}$ This model shows that when faced with the challenge of lowering costs under a global budget, hospital CFOs recognize the value of addressing the social needs of patients. Evaluation has shown that hospitals reduced their reliance on community physicians, especially in rural areas, where they found it easier to employ their own physicians, often via contract services.

The Maryland system is expected to improve not only the financial stability of hospitals but also patient outcomes, reduce readmissions, reduce the length of stay, and improve post-discharge follow up adherence. ${ }^{97}$

The hope is that the State of Maryland's CMS AllPayer Model will continue to successfully improve the quality of care and reduce program expenditures. ${ }^{97}$ The Maryland GBR methodology provides examples for states, illustrating how investing in the social needs of their patients can result in improved financial outcomes, allowing rural hospitals to remain open, while slowing the growth of healthcare spending.

Another novel innovative model to improve the viability of rural hospitals and meet the health care needs of rural residents is being tried in Pennsylvania. If suc- 
cessful, the model could provide a path towards stabilization for small and rural hospitals by lowering costs and improving quality of care. Pennsylvania lawmakers replaced their fee-for-service system with a multipayer global budget system based on each hospitals' net revenue. ${ }^{99}$ Under the plan, the hospital budget is calculated each year, with the hospital being paid $1 / 12$ of the total budget amount each month, giving hospitals a reliable revenue source. ${ }^{100}$

This system encourages hospitals and payers to invest in community health and health care delivery through greater access to preventive services, behavioral health services, and partnerships with community agencies in order to develop programs based on the needs of the community. CMS has agreed to provide the State of Pennsylvania up to $\$ 25$ million over five years to pilot the program. ${ }^{101}$ Over these five years, the rural hospitals are expected to save a minimum of $\$ 35$ million into Medicare costs. ${ }^{102}$ Initially, the hospitals recoup 100 percent of the programs' savings, but at the end of five years, the State and CMS will share the savings equally. ${ }^{103}$

\section{Enhancing Rural Health Workforce}

In addition to innovations in rural hospital funding, rural communities are also working creatively to help staff their clinics and hospitals with providers. A New England Journal of Medicine study found that the age distribution of rural physicians increased dramatically from 2000 to $2017 .{ }^{104}$ By 2017 , over half of physicians in rural areas were 50 years old and one in four were 60 years old. The study's authors predicted the shortages will only worsen in the coming decade without changes in policy and/or regulations.

Multiple debt forgiveness/loan repayment programs at both the federal and state level already exist. The National Health Service Corps (NHSC) Loan Repayment Program (LRP) recruits medical providers to practice in underserved areas. Clinicians receive up to $\$ 50,000$ for two years of full-time service or four years of half-time service at an approved Health Professional Shortage Area (HPSA). ${ }^{105}$ The clinician can amend their contract to receive up to $\$ 100,000$ for 5 years of service, though there is no guarantee it will be awarded. In addition to the NHSC, some states have begun offering repayment programs themselves, as a way to draw more medical students to their state. For example, an Oklahoma programs offers medical students $\$ 15,000$ per year for up to four years and a $\$ 1,000$ monthly stipend to family medicine residents if they practice in a rural area. ${ }^{106}$ Kentucky offers primary care physicians, dentists, and pharmacists up to $\$ 80,000$ for a full-time two-year commitment in a
HPSA; physician assistants, nurse practitioners, and certified nurse midwives, and mental health professionals up to $\$ 40,000$; and registered nurses, dental hygienists, and alcohol/substance abuse counselors up to $\$ 20,000 .{ }^{107}$

Outside of the financial incentives offered by the federal government and states, mentorship, or preceptor programs have a significant ability to improve the health care workforce shortage in rural America. These clinical programs, which are generally established by universities or hospital systems, occur after medical and dental students finish their core clinical rotations and choose a clinical specialty. The programs help students improve their clinical judgement and critical thinking, observe their mentors/preceptors in the clinical setting, and develop confidence in seeing patients. Programs vary in the amount of time required for a student to shadow a clinician and some provide housing and/or a stipend.

The University of Illinois - Rockford's Rural Medical Education (RMED) program and the University of Missouri's Rural Track Pipeline Program are two examples of programs that successfully recruit medical students to practice in rural areas. The RMED program was created in 1993 and has since graduated 226 physicians, $66 \%$ of whom chose primary care. It places medical students in a 16 -week rural preceptorship at one of their 25 rural teaching sites. RMED graduates are 8.5 times more likely to practice in a rural location and nearly 10 times more likely to practice in a HPSA. ${ }^{108}$ The University of Missouri's Rural Track Pipeline program includes a summer community program consisting of clinical and curriculum components to help students become familiar with rural medicine. Second year medical students work in a rural clinic with one or more community-based physicians in different specialties over the course of four to eight weeks. ${ }^{109}$ Since its inception in 1995,404 students have completed the program. Of the physicians that went through the program, approximately 55\% practice in a rural area. ${ }^{110}$ States and the federal government need to invest in more programs like RMED and Missouri's Rural Track Pipeline Program to get more students passionate about practicing medicine in rural areas.

\section{Addressing the Rural Opioid Epidemic}

Across the United States, the opioid crisis has claimed more lives than either the AIDS epidemic or motor vehicle deaths at their peaks. In 2017 alone, over 60,000 Americans died from opioid overdoses. ${ }^{111} \mathrm{~A}$ sizable amount of federal dollars have been awarded to states, allowing for a multitude of pilot programs 
focused on education, treatment, and prevention as ways to fight the opioid crisis. Thankfully, some states have begun to provide a framework that can be implemented across the country to reduce dependence, overdoses, and improve harm reduction programs.

One piece of that framework is a pilot program that seeks to address the opioid crisis through MAT (medication assisted treatment), which is the combination of behavioral therapy and medication (either methadone or buprenorphine). The Vermont system of MAT features nine regional hubs and over 75 local spokes, where doctors, nurses, and counselors offer long-term opioid use disorder (OUD) treatment. One of the issues with expanding MAT is the federal regulations that restrict it to two settings: Opioid Treatment Programs (OTPs) and Office Based Opioid Treatment (OBOT). Vermont uses hubs as OTPs and the spokes as OBOTs. The hubs provide more intense treatment, daily medications, and therapeutic support, assessment, medication dispensing, individual and group counseling, and trainings and consultations for the spoke providers. Working in conjunction with the hubs, the spokes integrate addiction care into general medical care. The spokes tend to be family medicine practices, with specialty outpatient addiction programs, and practices specializing in chronic pain. The physicians, nurse practitioners, and physician assistants are allowed to prescribe buprenorphine, oral naltrexone, or injectable Vivtrol. Vermont's program has over 6,000 participants and has reduced general health care expenditures and utilization, such as inpatient hospital admissions and outpatient emergency department visits for Medicaid beneficiaries with opioid addiction. ${ }^{112}$ MAT is cost effective because of the reduced rates of drug use, increased access to healthcare and other recovery support services, improved relationships and living conditions, and decreased involvement in high-risk behaviors. ${ }^{113}$ The hope is that the lessons learned from the Vermont's MAT system can be applied to other locations across the United States.

\section{Greater Focus on Social Issues Affecting Health}

The solutions to America's rural health challenges, however, need to concentrate on issues beyond those focused on providers and hospitals. In August 2018, Illinois launched a new statewide focus on the social issues affecting health. Influential stakeholders from government, health care, public health, philanthropy and academia met in Springfield, Illinois, for the first Illinois Rural Health Summit in nearly 15 years. The Summit focused on both traditional health care topics as well as the social and community issues affecting health. The ultimate goal was to build blueprints to improve the health of rural Illinois through sustainable, innovative programs and policies.

Feedback and conversation prior to the Summit helped identify that the most pressing health topics in rural Illinois mostly revolved around issues outside of traditional health care. Topics included traditional areas such as healthcare delivery, mental health, lack of health workforce, and the opioid epidemic. However, a strong focus also emerged on children's growth and development, healthy housing, nutrition and fitness, and caring for the aging population. The 1.5 day Summit used the insight of its attendees to craft solutions by framing these complicated issues, discussing strategic partnerships, designing measures, proposing innovative programs, and exploring sustainability. These issues and initial findings were detailed in the Rural Health Summit's first publication, "The State of Rural Illinois: Great Challenges and a Path Forward."114

Since releasing that report, the Illinois Rural Health Summit organizers Southern Illinois University School of Medicine Department of Population Science and Policy, the Illinois Department of Public Health, the Southern Illinois University Paul Simon Public Policy Institute, the University of Illinois at Chicago School of Public Health, and the Southern Illinois University School of Medicine Center for Rural Health and Social Service Development have collaborated with rural stakeholders, academics, business communities, legislators, community leaders and others to identify a series of policy recommendations to improve rural health.

Summits that broaden the understanding and take a more comprehensive look at rural health are key to creating multi-disciplinary and cross-disciplinary solutions that address these communities' increasingly complex problems. Illinois is just one example of many states trying to take a broader view of how to impact and sustain the health of rural America.

\section{Conclusion}

The state of rural health in America has great challenges, disparities only magnified by the current COVID-19 pandemic. However, a path forward exists that allows the federal government, individual state governments and their local communities to be innovative in how they fund health care systems, treat disease, and focus on issues beyond the four walls of the hospital and clinic. This path forward will require greater attention and energy paid both to the unique nature of rural areas as a whole and the complexities that exist within and among rural communities themselves. 
Federal and state policymakers will need to spend more time understanding rural communities with better and more focused research applied to the problems rural communities face. The research should start with a more comprehensive and encompassing definition of rural that allows communities and their residents to access funding and resources that are available. Additionally, more states should be provided the opportunity to innovate their health care funding structures using Maryland and Pennsylvania as potential models. The security of global budget funding structures would allow rural hospitals and clinics to have the investment to concentrate on their communities. Finally, solutions in improving rural health should place a greater emphasis on the social issues - economic development, housing, education, and culture - that more profoundly affect the health of rural residents. An opportunity exists now to build back rural communities better than they were before the COVID-19 pandemic. Urgent action is needed now.

The United States of America faces a historic election in 2020. The 15-20 percent of rural residents who live in 97 percent of the country's land mass need attention paid to their communities and their health. Success will require new partnerships, new definitions, and a new sense that innovation can happen in these communities. Our hope is that the lessons being learned in many states across our nation can serve as a design blueprint to create a more healthy and equitable rural America.

\section{Note}

The authors have no conflicts to disclose.

\section{References}

1. Centers for Disease Control and Prevention, "Rural Americans at Higher Risk of Death from Five Leading Causes," Centers for Disease Control and Prevention, January 12, 2017, available at <https://www.cdc.gov/media/releases/2017/p0112rural-death-risk.html $>$ (last visited July 31, 2020).

2. Health Policy Institute, "Rural and Urban Health," available at <https://hpi.georgetown.edu/rural/> (last visited January 29,2020 ).

3. Rural Health Information, "Barriers to Mental Health Treatment in Rural Areas - RHIhub Toolkit," available at <https:// www.ruralhealthinfo.org/toolkits/mental-health/1/barriers> (last visited July 31, 2020).

4. E. Moy, M. C. Garcia, B. Bastian, L. M. Rossen, D. D. Ingram, M. Faul, G. M. Massetti, et al., "Leading Causes of Death in Nonmetropolitan and Metropolitan Areas - United States, 1999-2014," MMWR. Surveillance Summaries 66, no. 1 (2017): 1-8, available at <https://doi.org/10.15585/mmwr. ss6601a1> (last visited July 31, 2020).

5. Centers for Disease Control, Cause of Death, available at <https://www.cdc.gov/ruralhealth/cause-of-death.html> (last visited July 31, 2020); H.E. Nasser, "What Is Rural America?" The United States Census Bureau, May 23, 2019, available at <https://www.census.gov/library/stories/2017/08/rural-america.html > (last visited July 31, 2020).

6. See Nasser, supra note 5.
7. A. Van Dam, "The Real (Surprisingly Comforting) Reason Rural America Is Doomed to Decline," The Washington Post, May 24, 2019, available at <https://www.washingtonpost. com/business/2019/05/24/real-surprisingly-comforting-reason-rural-america-is-doomed-decline/> (July 31, 2020).

8. E. Porter, "The Hard Truths of Trying to 'Save' the Rural Economy," The New York Times, December 14, 2018, available at <https://www.nytimes.com/interactive/2018/12/14/opinion/rural-america-trump-decline.html > (last visited July 31, 2020).

9. J. Adamy and P. Overberg, "Rural America Is the New 'Inner City," The Wall Street Journal, May 26, 2017.

10. M. Sheffield, "Health Care Tops Americans' List of Issue Priorities in New Poll," The Hill, May 16, 2019, available at <https:// thehill.com/hilltv/what-americas-thinking/444045-healthcare-tops-americans-list-of-issue-priorities-in-new-poll> (last visited July 31, 2020); A. Cancryn, "POLITICO-Harvard Poll: Health Care Costs are Top Priority Heading into Elections," Politico, February 9, 2020 available at <https://www.politico. com/news/2020/02/19/poll-health-care-election-115866> (last visited July 31, 2020).

11. M. Marmot, S. Friel, R. Bell, T.A. Houweling, and S. Taylor, "Commission on Social Determinants of Health. Closing the Gap in a Generation: Health Equity Through Action on the Social Determinants of Health," Lancet 372, no. 9650 (2008): 1661-1669, doi:10.1016/S0140-6736(08)61690-6; M. Silverstein, H.E. Hsu, and A. Bell, "Addressing Social Determinants to Improve Population Health: The Balance Between Clinical Care and Public Health," JAMA 322, no. 24 (2019): 23792380, doi:10.1001/jama.2019.18055.

12. Department of Health and Human Services, Office of Disease Prevention and Health Promotion "HealthyPeople.gov. 2020 topics and objectives: social determinants of health, objectives," available at <https://www.healthypeople.gov/2020/ topics-objectives/topic/social-determinants-of-health> (July 31, 2020); P. Braveman and L. Gottlieb, "The Social Determinants of Health: It's Time to Consider the Causes of the Causes," Public Health Reports 129, Suppl. 2 (2014): 19- 31.

13. See Moy et al., supra note 4.

14. C. Rothwell, J. Madans, and I. Arispe, "Data Access - Urban Rural Classification Scheme for Counties," Centers for Disease Control and Prevention. Centers for Disease Control and Prevention, June 1, 2017, available at < https://www.cdc.gov/nchs/ data_access/urban_rural.htm> (last visited July 31, 2020).

15. Centers for Disease Control and Prevention, "Rural Americans at Higher Risk of Death from Five Leading Causes," Centers for Disease Control and Prevention, January 12, 2017, available at <https://www.cdc.gov/media/releases/2017/p0112rural-death-risk.html> (last visited July 31, 2020).

16. Id.

17. E. Crouch, E. Radcliff, J. C. Probst, K. J. Bennett, and S. Hunt Mckinney, "Rural Urban Differences in Adverse Childhood Experiences Across a National Sample of Children," The Journal of Rural Health 36, no. 1 (2019): 55-64, available at $<$ https://doi.org/10.1111/jrh.12366> (last visited July 3, 2020),

18. Economic Research Service, "Rural Poverty and Well-Being," (2019), available at <https://www.ers.usda.gov/topics/ruraleconomy-population/rural-poverty-well-being/> (last visited July 31,2020 ).

19. See Rothwell et al., supra note 14.

20. C.A. Fontanella, D. L. Hiance-Steelesmith, G. S. Phillips, J. A. Bridge, N. Lester, H. A. Sweeney, and J. V. Campo, "Widening Rural-Urban Disparities in Youth Suicides, United States, 1996-2010," JAMA Pediatrics 169, no. 5 (2015): 466-473, available at <https://doi.org/10.1001/jamapediatrics.2014.3561> (last visited July 31, 2020).

21. See Moy et al. supra note 4

22. Id.

23. S. Monnat and K. Rigg, "The Opioid Crisis in Rural and Small Town America," University of New Hampshire - The Carsey School of Public Policy, November 7, 2018, available at 
$<$ https://carsey.unh.edu/publication/opioid-rural-smalltownus $>$ (last visited July 31, 2020).

24. C. Brems, M. E. Johnson, T. D. Warner, and L. Weiss Roberts, "Barriers to Healthcare as Reported by Rural and Urban Interprofessional Providers," Journal of Interprofessional Care 20, no. 2 (2006): 105-118, available at <https:// doi.org/10.1080/13561820600622208> (last visited July 31, 2020); N. Douthit, S. Kiv, T. Dwolatzky, and S. Biswas, "Exposing Some Important Barriers to Health Care Access in the Rural USA," Public Health 129, no. 6 (2015): 611-620, available at <https://doi.org/10.1016/j.puhe.2015.04.001> (last visited July 31, 2020); R. T. Goins, K. A. Williams, M. W. Carter, S. M. Spencer, and T. Solovieva, "Perceived Barriers to Health Care Access Among Rural Older Adults: A Qualitative Study," The Journal of Rural Health 21, no. 3 (2005): 206213, available at <https://doi.org/10.1111/j.1748-0361.2005. tb00084.x> (last visited July 31, 2020); G. Kilmer, L. Bynum, and A. Balamurugan, "Access to and Use of Eye Care Services in Rural Arkansas," The Journal of Rural Health 26, no. 1 (2010): 30-35, available at <https://doi.org/10.111 1/j.1748-0361.2009.00262.x> (last visited July 31, 2020); E. C. Ziller, N. J. Anderson, and A. F. Coburn, "Access to Rural Mental Health Services: Service Use and Out-of-Pocket Costs," The Journal of Rural Health 26, no. 3 (2010): 214-224, available at <https://doi.org/10.1111/j.1748-0361.2010.00291.x> (last visited July 31, 2020).

25. M. Cramer, J. Nienaber, P. Helget, and S. Agrawal, "Comparative Analysis of Urban and Rural Nursing Workforce Shortages in Nebraska Hospitals," Policy, Politics, छ Nursing Practice 7, no. 4 (2006): 248-260, available at <https://doi. org/10.1177/1527154406296481> (last visited July 31, 2020); See Douthit et al., supra note 24; S. M. Petterson, R. L. Phillips, A. W. Bazemore, and G. T. Koinis, "Unequal Distribution of the U.S. Primary Care Workforce," Robert Graham Center - Policy Studies in Family Medicine \& Primary Care, June 1, 2013, available at <https://www.graham-center.org/rgc/ publications-reports/publications/one-pagers/unequal-distribution-2013.html> (last visited July 31, 2020); "Rural Health Information Hub," Rural Healthcare Workforce Introduction, July 19, 2018, available at <https://www.ruralhealthinfo.org/ topics/health-care-workforce> (last visited July 31, 2020).

26. R. J. Bergin, J. Emery, R. C. Bollard, A. Zalounina Falborg, H. Jensen, D. Weller, U. Menon, et al., "Rural-Urban Disparities in Time to Diagnosis and Treatment for Colorectal and Breast Cancer," Cancer Epidemiology Biomarkers \& Prevention 27, no. 9 (2018): 1036-1046, available at <https://doi. org/10.1158/1055-9965.epi-18-0210> (last visited July 31, 2020); P. J. Joudrey, E. J. Edelman, and E. A. Wang, "Drive Times to Opioid Treatment Programs in Urban and Rural Counties in 5 US States," JAMA 322, no. 13 (2019): 1310-1312, available at <https://doi.org/10.1001/jama.2019.12562> (last visited July 31, 2020); E. C. Leira, D. C. Hess, J. C. Torner, and H. P. Adams, "Rural-Urban Differences in Acute Stroke Management Practices," Archives of Neurology 65, no. 7 (2008): 887-891, available at <https://doi.org/10.1001/archneur.65.7.887> (last visited July 31, 2020).

27. See Rothwell, et al. supra note 14.

28. See Petterson et. al. supra note 25 .

29. Rural Health Information Hub, Rural Data Explorer, available at <https://www.ruralhealthinfo.org/data-explorer>(last visited July 31, 2020).

30. Harvard T.H. Chan School of Public Health, "Views and Experiences of Rural Americans," Robert Wood Johnson Foundation, October 1, 2018, available at <https://www.rwjf.org/en/ library/research/2018/10/life-in-rural-america.html> (last visited July 31, 2020).

31. U.S. Census Bureau, "Urban and Rural." The United States Census Bureau, August 30, 2018, available at <https://www. census.gov/programs-surveys/geography/guidance/geo-areas/ urban-rural.html> (last visited August 3, 2020).

32. M. Ratcliffe C. Burd, K. Holder, and A. Fields, Defining Rural at the U.S. Census Bureau American Community Survey and Geography Brief, December 2016, available at <https:// www2.census.gov/geo/pdfs/reference/ua/Defining_Rural.pdf > (last visited August 3, 2020).

33. U.S. Census Bureau, "Stanley County South Dakota," available at <https://data.census.gov/cedsci/profile?q=Stanley $\% 20$ County,\%20South\%20Dakota\&g=0500000US46117> (last visited August 3, 2020)

34. Health Resources \& Services Administration, "Defining Rural Population," December 19, 2018, available at <https://www. hrsa.gov/rural-health/about-us/definition/index.html> (last visited August 3, 2020).

35. G. L. Hart, E. H. Larson, and D. M. Lishner, "Rural Definitions for Health Policy and Research," American Journal of Public Health 95, no. 7 (2005): 1149-1155, available at <https://doi. org/10.2105/ajph.2004.042432> (last visited August 3, 2020).

36. USDA ERS - Rural-Urban Commuting Area Codes, "RuralUrban Commuting Area Codes," October 24, 2019, available at <https://www.ers.usda.gov/data-products/rural-urbancommuting-area-codes.aspx> (last visited August 3, 2020).

37. U.S. Department of Health and Human Services, Federal Office of Rural Health Policy and Bureau of Health Workforce, "Rural Residency Planning and Development Program" available at <https://grants.hrsa.gov/2010/Web2External/ Interface/Common/EHBDisplayAttachment.aspx?dm rtc $=16 \& d m \_$attid $=$a03df4fa-db34-4fd1-b549-7a8808df4a37> (last visited August 3, 2020).

38. K. P. Wilkinson, The Community in Rural America (New York: Greenwood, 1991)

39. Institute of Medicine (US) Roundtable on Environmental Health Sciences, Research, and Medicine, Rebuilding the Unity of Health and the Environment in Rural America: Workshop Summary, J. Merchant, C. Coussens, D. Gilbert, eds. (Washington, DC: National Academies Press, 2006) at chapter 2, available at <https://www.ncbi.nlm.nih.gov/books/ NBK56967> (last visited August 3, 2020).

40. W. E. Zahnd, G. S. Mueller-Luckey, A. J. Fogleman, and W. D. Jenkins, "Rurality and Health in the United States: Do Our Measures and Methods Capture Our Intent?" Journal of Health Care for the Poor and Underserved 30, no. 1 (2019): 70-79, available at <https://doi.org/10.1353/hpu.2019.0008> (last visited August 3, 2020).

41. See Rural Health Information Hub, available at <https:// www.ruralhealthinfo.org/> (last visted August 3, 2020).

42. 42 C.F.R. $\$ 405.576$ (1983).

43. S. R. Thomas, R. Randolph, G. M. Holmes, and G. H. Pink, The Financial Importance of the Sole Community Hospital Payment Designation, Findings Brief, North Carolina Rural Health Program, November 2016. [Figure out 340B status for $\mathrm{SCHs}]$

44. Id.

45. See Thomas et al. supra note 43 .

46. 42 C.F.R. $\$ 412.96$ (1983)

47. Centers for Medicare and Medicaid Services, Department of Health and Human Services, "Rural Referral Center Program," no. 006742, May 2014, available at <https://static1.squarespace.com/static/5c13fd $4150 a 54$ f21cfo140ad/t/5c140bOc03c e64b47cc3173a/1544817421707/CMS_Fact_Sheet_--_RRC. pdf > (last visited Jan. 13, 2020).

48. Rural Hospital Coalition, "What is an RRC?" available at $<$ https://www.ruralhospitalcoalition.com/what-is-an-rrc $>$ (last visited Jan. 7, 2020).

49. See supra note 46 .

50. See supra note 47 .

51. Id.

52. $I d$.

53. Rural Health Information Hub, "Critical Access Hospitals," available at <https://www.ruralhealthinfo.org/topics/criticalaccess-hospitals\#benefits $>$ (last updated Aug. 20, 2019).

54. Balanced Budget Act of 1997, Pub. L. No. 105-133, 11 Stat. 371, 370-371 (1997); see also infra note 78

55. M. Jordan, "Rural Areas Brace for a Shortage of Doctors Due to Visa Policy," The New York Times, March 18, 2017. 
56. American Hospital Association, "Small or Rural Hospitals," available at <https://www.aha.org/advocacy/small-or-rural> (last visited Sep. 4, 2019).

57. Medicare Prescription Drug, Improvement, and Modernization Act of 2003, Pub. L. No. 108-173, §410A, 117 Stat. 2273 (2003).

58. Centers for Medicare and Medicaid Services, U.S. Department of Health and Human Services, "Rural Community Hospital Demonstration," available at $<$ https://innovation.cms.gov/initiatives/Rural-Community-Hospital/> (last updated July 31, 2019).

59. Athena Health, "Community Hospitals Knowledge Hub," available at $<$ https://www.athenahealth.com/knowledge-hub/ community-hospitals/what-are-community-hospitals $>$ (last visited Sep. 4, 2019).

60. J. Ali-Dinar, CMS Creates More Rural Innovation - Round 3 - Rural Community Hospital Demonstration Program to Meet Rural Needs, Racmonitor, May 24, 2017, available at <https:// www.racmonitor.com/cms-creates-more-rural-innovationround-3-rural-community-hospital-demonstration-programto-meet-rural-needs> (last visited August 3, 2020).

61. Id.

62. S. Morse, Healthcare Finance, "CMS Seeks Rural Hospitals' Participation in Medicare Inpatient Demonstration," April 18, 2017, available at <https://www.healthcarefinancenews. com/news/cms-seeks-rural-hospitals-participation-medicareinpatient-demonstration> (last visited August 3, 2020) (the twenty states include: Alaska, Arizona, Arkansas, Colorado, Idaho, Iowa, Kansas, Maine, Mississippi, Montana, Nebraska, Nevada, New Mexico, North Dakota, Oklahoma, Oregon, South Dakota, Utah, Vermont, and Wyoming).

63. Pub. L. No. 108-173, 117 Stat 2273; Centers for Medicare and Medicaid Services, U.S. Department of Health and Human Services, Rural Community Hospital Demonstration, available at <https://innovation.cms.gov/Files/x/rch-faqs.pdf> (last visited Oct. 16, 2019).

64. See CMS supra note 63

65. S. Desai and J. M. McWilliams, "Consequences of the 340B Drug Pricing Program," New England Journal of Medicine 378, No. 6 (2018): 539-548.

66. American Hospital Association, Fact Sheet: The 340B Drug Pricing Program, January 2019, available at <https://www. aha.org/system/files/2019-01/fact-sheet-340b-0119.pdf> (last visited August 3, 2020).

67. Managed Healthcare Executive, "340B Program Helps Rural Hospitals Stay Afloat," June 23, 2019, available at $<$ https://www.managedhealthcareexecutive.com/hospitalsproviders/34ob-program-helps-rural-hospitals-stay-afloat> (last visited August 3, 2020).

68. J. M. Devin, "Cuts to the 340B Program Threaten Rural Hospitals," Washington Examiner, May 25, 2018, available at <https://www.washingtonexaminer.com/opinion/op-eds/cutsto-the-340b-program-threaten-rural-hospitals> (last visited August 3, 2020)

69. Rural Health Information Hub, "Rural Health Clinics (RHCs)," available at <https://www.ruralhealthinfo.org/topics/ruralhealth-clinics $>$ (last visited August 3, 2020).

70. Centers for Medicare and Medicaid Services, Department of Health and Human Services "Rural Health Clinic," available at <https://www.cms.gov/Outreach-and-Education/Medicare-Learning-Network-MLN/MLNProducts/downloads/ RuralHlthClinfctsht.pdf> (last visited August 3, 2020).

71. Azalea Health, "What Is An RHC \& Why Are They So Important," available at <https://www.azaleahealth.com/blog/whatis-rhc/> (last visited August 3, 2020).

72. Id.

73. See Centers for Medicare \& Medicaid Services, supra note 47, at 4

74. Id.

75. E. Duke, Health Resources and Services Association, U.S. Department of Health and Human Services, Comparison of the Rural Health Clinic and Federally Qualified Health Center Programs, June 2006.

76. B. Wright, "Who Governs Federally Qualified Health Centers?” Journal of Health, Politics, Policy and Law 38, no. 1 (2013): 27-55, available at <https://www.ncbi.nlm.nih.gov/ pmc/articles/PMC5602556/pdf/nihms902548.pdf> (last visited August 3, 2020)

77. Centers for Medicare and Medicaid Services, U.S. Department of Health and Human Services, "Federally Qualified Health Center," Sept. 2019, available at <https://www.cms.gov/Outreach-and-Education/Medicare-Learning-Network-MLN/ MLNProducts/downloads/fqhcfactsheet.pdf> (last visited August 3, 2020).

78. The Definitive Blog, "How Many Federally Qualified Health Centers Are There?" July 1, 2019, available at <https://blog. definitivehc.com/how-many-fqhes-are-there> (last visited August 3, 2020).

79. Rural Health Information Hub, "Federally Qualified Health Centers (FQHCs) and the Health Center Program," (last visited Jan. 9, 2020), available at <https://www.ruralhealthinfo. org/topics/federally-qualified-health-centers $>$ (last visited August 3, 2020)

80. Id.

81. Id.

82. A. Ellison, "State-by-State Breakdown of 113 Rural Hospital Closures," Becker's Hospital CFO Report, August 26, 2019, available at <https://www.beckershospitalreview.com/ finance/state-by-state-breakdown-of-113-rural-hospital-closures-082619.html> (last visited August 3, 2020); The Cecil Sheps Center for Health Services Research, "172 Rural Hospital Closures: January 2005 - Present (130 since 2010)" available at <https://www.shepscenter.unc.edu/programs-projects/ rural-health/rural-hospital-closures/> (last visited August 3, 2020).

83. K. Siegler, "Doctor Shortage In Rural Arizona Sparks Another Crisis In 'Forgotten America," National Public Radio, July 14, 2017, available at <https://www.npr.org/sections/healthshots/2017/07/14/535792864/doctor-shortage-in-rural-arizona-sparks-another-crisis-in-forgotten-america> (last visited August 3, 2020).

84. J. Healy, "It's 4 A.M. The Baby's Coming. but the Hospital Is 100 Miles Away," New York Times, July 17, 2018, available at <https://www.nytimes.com/2018/07/17/us/hospital-closingmissouri-pregnant.html?emc=edit th $180717 \&$ nl=todayshea dlines\&nlid=334258010717> (last visited August 3, 2020)

85. See Centers for Disease Control, supra note 1.

86. See Moy et al., supra note 4.

87. RUPRI Rural Policy Research Institute, "Considerations for Defining Rural Places in Health Policies and Programs," available at <https://rupri.public-health.uiowa.edu/publications/policypapers/Considerations\%20For\%20Defining $\% 20$ Rural\%20Places.pdf $>$ (last visited August 3, 2020).

88. C. Merrett, "Demographic and Economic Trends in Illinois" plenary at Healthy Communities Conference, Platteville, WI, July 1, 2015, available at <http://www.rwhc.com/mediasite/6PPT\% 20-\% 20Chris\%20Merrett\% 20-\%20plenary\% 20am. pdf> (last visited August 3, 2020).

89. Illinois Health and Hospital Association, Advancing Rural Health in Communities across Illinois (2018), available at <https://www.team-iha.org/files/non-gated/memberresources/small-rural-hospitals-backgrounder.aspx > (last visited August 3, 2020).

90. Id.

91. Id.

92. G.M. Holmes et al., "The Effect of Rural Hospital Closures on Community Economic Health," Health Services Research 41, no. 2 (2006): 467-485, doi:10.1111/j.1475-6773.2005.00497.x

93. D. Mosley and D. DeBehnke, "Rural Hospital Sustainability: New Analysis Shows Worsening Situation for Rural Hospitals, Residents," Navigant, Feb. 2019, available at <www.navigant. com/-/media/www/site/insights/healthcare/2019/navigant- 
rural-hospital-analysis-22019.pdf> (last visited August 3, 2020).

94. The community essentiality was defined as the trauma status, service to vulnerable populations, geographic isolation, and economic impact.

95. Supra note 93.

96. Id, p.21-22.

97. S. Haber et, al., Centers for Medicare and Medicaid, U.S. Department of Health and Human Services, "Evaluation of the Maryland All-Payer Model Volume I: Final Report", November 2019, available at <https://downloads.cms.gov/files/mdallpayer-finalevalrpt.pdf $>$ (last visited August 3, 2020).

98. Centers for Medicare and Medicaid, U.S. Department of Health and Human Services, "Maryland All-Payer Model," available at <https://innovation.cms.gov/initiatives/Maryland-All-Payer-Model > (last visited August 3, 2020).

99. K. M. Murphy, L.S. Hughes, and P. Conway, "A Path to Sustain Rural Hospitals," JAMA 319, no. 12 (2018): 1193-1194.

100. $I d$.

101. $I d$.

102. $I d$

103. $I d$

104. L. Skinner et al., "Implications of an Aging Rural Physician Workforce," New England Journal Medicine 381, no. 4 (2019): 299-301.

105. National Health Service Corps Loan Repayment Program FAQ, available at <https://nhsc.hrsa.gov/loan-repayment/ nhsc-loan-repayment-program.html> (last visited August 26, 2020).

106. Y. Fedyanova, "Incentivizing Young Doctors to Practise in Underserved Areas," Canadian Medical Association Journal 190, no. 7 (2018): E203, doi:10.1503/cmaj.109-5563.

107. University of Kentucky College of Medicine "Kentucky State Loan Repayment Program," available at <http://ruralhealth. med.uky.edu/kentucky-state-loan-repayment-program> (last visited August 3, 2020)

108. Lewin Group, Inc., Provider Retention in High Need Areas, December 14, 2014, available at <https://aspe.hhs.gov/ system/files/pdf/116861/NHSC\%20Final\%20Report $\% 20$ 508\%20compliance\%20July_21_2015.pdf> (last visited August 3, 2020).

109. University of Missouri Health School of Medicine, Rural Track Pipeline Program, available at $<$ https://medicine.missouri.edu/sites/default/files/RuralTrackPipeline_2015.pdf $>$ (last visited August 3, 2020).

110. Rural Track Pipeline Program, available at $<$ https://medicine.missouri.edu/education/rural-track-pipeline-program> (last visited August 3, 2020).

111. KFF, Opioid Overdose Deaths by Type of Opioid, available at $<$ https://www.kff.org/other/state-indicator/opioid-overdosedeaths-by-type-of-opioid/?currentTimeframe $=0$ \&sortModel $=$ $\% 7 \mathrm{~B} \% 22$ colId $\% 22: \% 22$ Location $\% 22, \% 22$ sort $\% 22: \% 22$ asc $\%$ $22 \% 7 \mathrm{D}>$ (last visited August 3, 2020).

112. Hub and Spoke | Blueprint for Health, "Hub and Spoke," November 7, 2019, available at <https://blueprintforhealth vermont.gov/about-blueprint/hub-and-spoke> (last visited August 3, 2020).

113. Illinois Department of Public Health, State of Illinois Opioid Action Plan, September 2017, available at <http://dph.illinois. $\mathrm{gov} /$ sites/default/files/publications/Illinois-Opioid-ActionPlan-Sept-6-2017-FINAL.pdf> (last visited August 3, 2020).

114. The State of Rural Health in Illinois: Great Challenges and a Path Forward, available at <https://www.siumed.edu/sites/ default/files/u9451/rhs_stateofillinois_final1115.pdf> (last visited August 3, 2020).

115. The authors used this table from Evaluation of the Maryland All-Payer Model. Volume I: Final Report, supra note 97. 